\title{
LEITURA E ESCRITA: UMA DESCOBERTA QUE PODE SER REALIZADA NO AMBIENTE ESCOLAR
}

\author{
READING AND WRITING: A DISCOVERY THAT CAN BE PERFORMED IN \\ THE SCHOOL ENVIRONMENT
}

\section{LECTURA Y ESCRITA: UNA DESCUBRIDA QUE PUEDE REALIZADA EN EL MEDIO AMBIENTE ESCOLAR}

\author{
Suzana Abrunhosa \\ Graduação em Letras - Faculdades Integradas de Jaú \\ Mestra em Processos de Ensino, Gestão e Inovação \\ Docente das Faculdades Integradas de Jaú \\ e-mail: sabrunhosa@uol.com.br
}

\begin{abstract}
RESUMO
A falta do hábito de leitura por parte de muitos educandos é uma lastimável constatação que os docentes fazem cotidianamente e o mesmo se verifica quanto à prática da escrita. Sendo assim, uma mudança de perspectiva sobre as concepções de leitura se faz necessária, para que os conceitos redutores do ato de ler não gerem leitores que apenas reproduzam significados. Apesar das dificuldades, o ambiente escolar se destaca por ser o local onde crianças e adolescentes podem obter o preparo adequado para compreender os vários gêneros textuais que circulam socialmente e o papel mediador do professor é de suma importância. Para compreender o valor da leitura serão utilizados como apoio teórico os conceitos preconizados por Chartier (1999), Abreu (2006), Soares (2005), Klebis (2008), Silva (1999;2003;2017), Cagliari (1989) e Geraldi (1993). Também serão apresentadas as orientações propostas pelos PCNs (1998) e, sobre sequência didática, o procedimento sugerido por Dolz, Noverraz e Schneuwly (2004).
\end{abstract}

Palavras-chave: Práticas de leitura. Concepções de leitura. Ambiente escolar.

\section{ABSTRACT}

The lack of reading habits on the part of many students is a pitiful observation that teachers do daily and the same is true of writing practice. Thus, a change of perspective on the conceptions of reading becomes necessary, so that the concepts reducing the act of reading do not generate readers who only reproduce meanings. Despite the difficulties, the school environment stands out because it is the place where children and adolescents can obtain adequate preparation to understand the various textual genres that circulate socially and the mediating role of the teacher is of paramount importance. In order to understand the value of reading, the concepts advocated by Chartier (1999), Abreu (2006), Soares (2005), Klebis (2008), Silva (1999, 2003, 2017), Cagliari (1993). The guidelines proposed by the PCNs (1998) and, on didactic sequence, the guidance

$$
\text { RELEDUC | ISE | v. } 2 \text { | n. } 1 \text { | fev. } 2019
$$


suggested by Dolz, Noverraz and Schneuwly (2004) will also to be presented. Keywords: Reading practices. Conceptions of reading. School environment.

\section{RESUMEN}

La falta del hábito de lectura por parte de muchos educandos es una lástima constatación que los docentes hacen cotidianamente y lo mismo se verifica en cuanto a la práctica de la escritura. Siendo así, un cambio de perspectiva sobre las concepciones de lectura se hace necesaria, para que los conceptos reductores del acto de leer no generen lectores que sólo reproducen significados. A pesar de las dificultades, el ambiente escolar se destaca por ser el lugar donde niños y adolescentes pueden obtener la preparación adecuada para comprender los diversos géneros textuales que circulan socialmente y el papel mediador del profesor es de suma importancia. Para comprender el valor de la lectura serán utilizados como apoyo teórico los conceptos preconizados por Chartier (1999), Abreu (2006), Soares (2005), Klebis (2008), Silva (1999; 2003; 2017), Cagliari (1989) y Geraldi (1993). También se presentarán las orientaciones propuestas por los PCN (1998) y, sobre secuencia didáctica, la orientación sugerida por Dolz, Noverraz y Schneuwly (2004). Palabras clave: Prácticas de lectura. Conceptos de lectura. Ambiente escolar.

\section{INTRODUÇÃO}

Cotidianamente, as pessoas estão cercadas por livros, rodeadas por palavras, esperando por alguém que as decifre ou busque um sentido novo. Experiências de práticas de leituras e escrita são vivenciadas em diferentes espaços, entretanto muitas vezes é difícil lidar com as palavras, escorregadias, fluidas, cortantes e instigantes.

E o que dizer das crianças e dos adolescentes? Quantas práticas de leitura e escrita são proporcionadas em casa, na escola, nas redes sociais! E nesse descobrir da leitura e da escrita, especificamente no ambiente escolar, o docente tem papel essencial, pois é ele que pode ampliar as competências linguísticas do educando, especialmente, ler, escrever e interpretar textos.

$\mathrm{O}$ ato de ler não nasce com o ser humano. É uma habilidade que precisa ser estruturada, conquistada, o que revela seu cunho social. Em vista disso, a leitura e a escrita são reconhecidas como práticas culturais essenciais para insertar o indivíduo na sociedade, podendo ocasionar transformações, diminuir a desigualdade e proporcionar a participação responsável das pessoas no ambiente coletivo.

Hoje, a leitura é imprescindível no dia a dia, em todos os momentos, e tornou-se obrigatória no currículo escolar. Apesar disso, Abreu (2006) relata que a noção do valor da leitura modificou-se com o passar do tempo. No século XVIII, alguns cientistas, como Tissot e Heinzemann, admitiam que o ato de ler era perigoso para a saúde, trazendo 
prejuízo para os olhos, os nervos e o cérebro. $\mathrm{O}$ ideal seria ler pouco e fazer exercícios para evitar atordoamento e irritabilidade. Além dos supostos problemas físicos, a leitura poderia propiciar a conscientização de trabalhadores, das mulheres e dos desvalidos, ameaçando os poderosos senhores que detinham o poder.

O incentivo à leitura é uma preocupação constante, visto que é também através dela que o indivíduo se apodera do saber já produzido pela humanidade, e a escola é reconhecidamente um dos ambientes mais favoráveis para se trabalhar com a leitura, possibilitando a formação de leitores autônomos, críticos, que interpretem e compreendam o texto que têm em mãos, assim propiciando o crescimento pessoal do educando, sua inserção social. Por isso deve estar presente em todos os momentos do ensino.

Em virtude da relevância desse tema, várias campanhas e programas de incentivo à leitura em nível nacional surgiram com o propósito de estimular sua prática. Entre eles, podem ser destacados o Programa Nacional de Incentivo à Leitura, (PROLER, 1992), o PRÓ-LEITURA (1992), o Programa Nacional Biblioteca da Escola (PNBE, 1997) e o Plano Nacional do Livro e Leitura (PNLL, 2006) e as campanhas "Tempo de Leitura" (2001) e "Viva Leitura" (2005).

Apesar desses estímulos, o resultado não tem sido satisfatório e o problema com relação à leitura continua sendo grave no Brasil. É preciso que haja um trabalho sério, tendo como mediadora a escola, com professores bem preparados, os quais poderão orientar as práticas leitoras mais adequadas.

Em vista do exposto, este artigo busca despertar a reflexão sobre alguns conceitos de leitura, contribuindo assim com a prática dos docentes em sala de aula quanto ao ensino de leitura e também de escrita, lembrando que não há um único método totalmente abrangente que atenda aos propósitos e práticas desse ensino. A ação pedagógica do professor deve ser bem preparada, proporcionando aos alunos o desenvolvimento das habilidades de leitura e escrita de diferentes gêneros textuais.

\section{ALGUMAS CONCEPÇÕES DE LEITURA}

Há diversas concepções de leitura que podem auxiliar o docente ao conduzir as atividades de leitura em sala de aula. Entre elas, pode-se citar a de Martins, para quem a leitura ocorre verdadeiramente ...

$$
\text { RELEDUC | ISE | v. } 2 \text { | n. } 1 \text { | fev. } 2019
$$


quando começamos a estabelecer relações entre as experiências e a tentar resolver os problemas que se nos apresentam - aí então estamos procedendo leituras, as quais nos habilitam basicamente a ler tudo e qualquer coisa (MARTINS, 1986, p. 17).

A autora também afirma haver três níveis de leitura, os quais estão interrelacionados e são simultâneos: sensorial, emocional e racional. Dessa forma, a leitura é um ato dinâmico e o leitor estabelece, ao ler, relações com os mais diversos gêneros textuais.

Kleiman (1997) igualmente ressalta que a leitura é um conjunto de processamento de três níveis de conhecimento: o linguístico, o textual e o prévio, estimulados de modo interligado, o que proporciona a compreensão integral do texto. Assim sendo, essas concepções demonstram ser a leitura uma atividade que emprega diversificados conhecimentos e sentidos para efetivar-se.

Roger Chartier (1999) considera ser a leitura sempre apropriação, invenção e produção de significados. Segundo o autor, se pensarmos na leitura como uma prática, há a cada dia milhões de indivíduos que realizam milhões de atos de leitura. As maneiras de ler diferenciam-se ao longo dos séculos e a leitura sofreu mudanças nas formas de representação, como é o caso do cinema, da fotografia e das pinturas.

Soares enfatiza que "[...] um mesmo texto multiplica-se em infinitos textos, tantos textos quantas leituras houver. Cada leitura construirá um novo texto, produto de determinações múltiplas" (2005, p.28). O leitor, ao ter um texto em mãos, passa por uma experiência particular e, em virtude de seus conhecimentos, de suas experiências e de seus valores, poderá transformar o significado do texto em algo novo, diferenciado, após várias leituras. Como bem disse o filósofo Heráclito de Èfeso, "Ninguém entra em um mesmo rio uma segunda vez, pois quando isso acontece já não se é o mesmo, assim como as águas que já serão outras. ” Na segunda vez, nem o homem nem o rio são mais os mesmos e isso também ocorre ao se ler um texto.

Da mesma forma, Cagliari salienta que "a leitura é uma atividade profundamente individual e duas pessoas dificilmente fazem uma mesma leitura de um texto, mesmo científico" (1989, p.150). Cada leitor, com suas experiências e vivências, atribuirá um sentido ao texto que tem em mãos, por isso a leitura é uma prática produtora de sentidos diferentes, possibilitando a construção de novos conhecimentos.

Já Silva faz um alerta para que os professores tomem cuidado com as concepções redutoras de leitura, que desprezam "elementos fundamentais da leitura, diminuindo a sua

$$
\text { RELEDUC | ISE | v. } 2 \text { | n. } 1 \text { | fev. } 2019
$$


complexidade processual” (1999, p.12). Para ele, as definiçõos redutoras de leitura são: ler é traduzir a escrita em fala (o leitor, na escola, não consegue compreender as ideias aludidas nos textos); ler é decodificar mensagens (há o desprezo pelos interesses e pelo repertório prévio dos alunos, indicando a passividade do leitor em relação à produção de sentido); ler é dar respostas a sinais gráficos (há uma resposta protocolar, no livro didático, respaldada pelo professor e não se permitem diferentes interpretações); ler é extrair a ideia central (na verdade, há variados tipos de organização textual e a ideia principal nem sempre aparece nitidamente); ler é seguir os passos da lição do livro didático (ideia equivocada do processo de leitura) e ler é apreciar os clássicos (o leitor crítico deve apreciar a enorme quantidade de gêneros que circulam na sociedade, incluindo os de literatura). Além disso, Silva (1999) lembra que a leitura é uma prática social e histórica, que sofre transformações com o decorrer do tempo, suscitando reflexões e desafios ao processo de ensino-aprendizagem da leitura.

O autor propõe uma concepção interacionista de leitura, em que o texto age sobre o leitor e o leitor age sobre o texto, envolvendo um projeto de compreensão e um processo de interpretação. Assim, essa concepção é a que deveria ser valorizada pela escola, para não haver a formação de leitores ingênuos que somente reproduzem o que lhes é transmitido.

\section{LEITURA NO AMBIENTE ESCOLAR}

Na sociedade brasileira, lamentavelmente, o espaço escolar inúmeras vezes não tem atraído a criança muito menos o adolescente. Talvez pela razão de que muitos professores não consigam articular o ensino e a aprendizagem da leitura e da escrita às experiências cotidianas de práticas de leitura e escrita vivenciadas pelo educando.

Primeiramente, relembro o que os Parâmetros Curriculares Nacionais de Língua Portuguesa de $5^{\mathrm{a}}$ a $8^{\mathrm{a}}$ Série recomendam a respeito da leitura:

... é necessário mostrar ao leitor que a leitura não é simplesmente uma disciplina da sua grade curricular escolar; transpõe os muros da escola para os diferentes espaços de convívio social. E cabe ao professor permitir e incentivar diferentes leituras do mesmo texto, ou seja, realizar um trabalho que faça seu aluno consolidar as estratégias de leitura. Uma prática de leitura que não desperte e cultive o desejo de ler não é uma prática pedagógica eficiente. (BRASIL, 1998, p. 17). 
Os estudantes precisam ter a percepção de que a leitura é uma necessidade diária em suas relações sociais e, nas aulas de leitura, não basta ler e escrever, mas sim construir sentidos. Entretanto, como fazê-lo? É preciso, primeiramente, que o professor se disponha a sair de uma postura mais tradicional, em que ensinar é simplesmente transmitir um saber, sem considerar que o aluno é um ser de "carne e osso", com histórias, muitas e diversas histórias.

Cintra, em relação ao trabalho com a leitura no espaço escolar, adverte que Pela forma como se trabalha a leitura, em geral, o aluno ainda não a reconhece
como lazer, como possibilidade de alimentação da imaginação, menos ainda
como lugar de produção de conhecimento, capaz de alterar sua bagagem
intelectual, a ponto de promover apropriação daquilo que leu. (CINTRA, 2011,
p.199)

Vários autores também têm demonstrado preocupação com relação à prática da leitura nas escolas. Klebis (2008) afirma ser preciso que as práticas escolares em torno da leitura na escola deixem marcas agradáveis, fazendo com que a construção das relações entre alunos/leitores e livros seja algo visto como essencial na vida social dos discentes. Cabe às escolas, às bibliotecas escolares e, sobretudo aos professores, propiciar as melhores relações possíveis, para que haja um envolvimento entre alunos-leitores e livros, despertando o prazer de ler. Professores devem fazer um convite à leitura aos alunos.

A forma como a leitura literária se apresenta no ambiente escolar também tem gerado preocupações em diversos pesquisadores. Mafra (2003) constata uma realidade inquietante: o mundo de hoje é muito mais atraente para crianças e adolescentes que a escola. Percebe-se isso, principalmente, com relação à leitura de obras clássicas. $\mathrm{O}$ conceito de literatura veiculado nas aulas de Língua Portuguesa é algo como um patrimônio a ser passado de geração a geração, com uma interpretação oficial.

$\mathrm{O}$ autor recomenda uma nova forma de pensar literatura. É importante que o adolescente conviva com a diversidade literária, enxergando sua própria trajetória de leituras, a qual não pode ser desprezada. É fundamental que haja uma relação de interação entre texto e leitor, para que o trabalho com a literatura na escola dê resultados positivos.

Segundo Mafra (2003), a escola não tem marcado encontro com o mundo do jovem e, com isso, há a dificuldade na formação de sujeitos mais críticos e, consequentemente, do sujeito-leitor. O Ensino Médio traz uma literatura clássica que é estranha aos adolescentes e a imagem de literário passada na sala de aula está relacionada ao estudo do vocabulário, ao estilo, a fazer resumo, resenha, responder questionário e fichamento. 
O professor, delimitando autores e títulos prestigiados, acaba por segregar outros. O pesquisador reforça ainda que se a interação entre o leitor, que possui uma história de leituras, com o texto não existe, o trabalho com a literatura na escola não dá o resultado esperado.

O que se observa é que a grande maioria dos jovens enxerga a leitura das obras clássicas como algo entediante, enfadonho e é feita uma cobrança de leitura que não possui significado para eles. Faz-se necessária uma nova forma de se pensar literatura, abrindo espaço inclusive para a literatura de massa. É importante que o adolescente conviva com a diversidade literária; enxergue sua trajetória de leituras. Mafra (2003) assevera ainda que há a ausência da escola na intermediação jovem-livro e que a leitura do adolescente geralmente se prende à chamada literatura de massa, aos best-sellers, a revistas que não são valorizadas no ambiente escolar. Mas são leituras. Talvez não a leitura que os professores desejam e esperam que seus alunos façam, mas são leituras. Dessa forma, é relevante a mudança de como a escola encara a leitura de textos literários. Ela pode e deve propiciar a ampliação do conceito de leitura que o jovem tem.

Aqui, pensando em leitura e professores, merece ser citado Ezequiel Theodoro da Silva, o qual em sua obra, Leitura na escola e na biblioteca, destaca que

[...] a condição básica para ensinar o aluno a ler diz respeito à capacidade de leitura do próprio professor. Mais especificamente, para que ocorra um bom ensino da leitura é necessário que o professor, seja, ele mesmo, um bom leitor [...] - isto porque os nossos alunos necessitam do testemunho vivo dos professores no que tange à valorização e encaminhamento de suas práticas de leitura. (SILVA, 2003, p. 109)

Como um professor poderá estimular os alunos a percorrerem as veredas da leitura, se ele próprio não gosta de ler? Como poderá ampliar as competências linguísticas do educando?

E o que dizer das práticas de escrita? Muitos professores não diversificam as atividades, sempre pedindo que se faça a mesma coisa. A produção de texto se torna algo maçante, focalizando as mesmas temáticas. Parece não haver possibilidades de mudanças. Podemos perceber essa situação representada em um livro adorável e divertido de Christiane Gribel, Minhas férias, pula uma linha, parágrafo (1999). Nas páginas oito e nove, o protagonista, o garoto Guilherme, aluno da $6^{\mathrm{a}}$ série B (correspondente ao $7^{\circ}$ ano do ensino fundamental), descreve seu primeiro dia de aula:

"A professora puxou a cadeira dela e se sentou.

$$
\text { RELEDUC | ISE | v. } 2 \text { | n. } 1 \text { | fev. } 2019
$$


Atrás dela, no quadro-negro, eu vi decretado o fim das nossas férias e o fim do nosso primeiro dia de aula sem aula. Estava escrito:

\section{Redação: escrever trinta linhas sobre as férias.}

Eu sabia que as férias de ninguém iam ser mais as mesmas na hora que virassem redação. É simples: férias é legal, redação é chato. Quando a gente transforma as nossas férias numa redação, elas não são mais as nossas férias, são a nossa redação. Perdem toda a graça.

(...)

Além do mais, eu tenho certeza de que a professora nem quer saber de verdade como foram as nossas férias. Ela quer só saber como é a nossa letra e se a gente tem jeito para escrever redação. Aqueles dois meses inteirinhos de despreocupações estavam prestes a virar trinta linhas de preocupações com acentos, vírgulas, parágrafos e ainda por cima com a letra ilegível depois de tanto tempo sem treino."

Gribel (1999), com o texto acima, retratou o que ocorre muitas vezes nas salas de aula. Tira-se o prazer de escrever. Produzir um texto é muito mais do que somente verificar se o aluno emprega adequadamente a norma padrão da Língua Portuguesa, se ele sabe juntar frases gramaticalmente corretas e tem o domínio do código alfabético.

Quando se produz um texto, algumas ideias são fundamentais, segundo Geraldi (1993, p. 137): "ter o que dizer"; "uma razão para dizer o que se tem a dizer"; "se tenha para quem dizer o que se tem a dizer". Ainda conforme o autor, há duas concepções diferentes de escrita: a que o aluno escreve "para a escola" (redação), com frases que não são dele, para o professor atribuir uma nota; e a que escreve "na escola" (produção de texto), em que, mesmo se descuidando das normas gramaticais, escreve algo que expressa sua visão de mundo. O educando precisa sentir que escrever é imprescindível nos dias atuais.

No entanto, como ensinar a produzir textos se o receio de escrever não é encontrado somente entre os alunos? Muitos docentes também vacilam na hora de escrever. Há professores que não são leitores e nem sentem prazer com atividades de leitura e de escrita. Talvez traumas que a escola proporcionou?

O professor deve estar em constante processo de formação, buscando sempre se qualificar. Deve ser um participante ativo na aprendizagem do aluno, e para isso é preciso que perceba a importância de sua própria formação. $O$ fazer docente inclui não só o conhecimento dos conteúdos da disciplina que leciona, mas também como abordá-los de 
maneira contextualizada, com o domínio de diferentes métodos de ensino. O professor precisa saber escolher o mais indicado dependendo dos temas abordados e dos alunos com os quais está trabalhando.

Atualmente, com tantos avanços tecnológicos, as crianças e os jovens têm acesso a um número gigantesco de informações, e a escola precisa ser mais atrativa, apresentar a leitura de forma mais significativa aos alunos, relacionando os textos trabalhados em sala de aula à realidade deles, proporcionando sua formação de leitores e produtores de textos.

Uma das formas de se alcançar esse objetivo pode ser encontrada no texto referente à sequência didática, de Dolz, Noverraz e Schneuwly (2004). Já na introdução há a seguinte afirmativa: é possível ensinar a escrever textos e a exprimir-se oralmente em situações públicas escolares e extraescolares, a partir do momento em que o aluno entender o gênero que está sendo trabalhado, qual a sua estrutura, sua finalidade, seu interlocutor. Para isso, os professores devem oferecer múltiplas e variadas situações de escrita e de fala, partindo do que os alunos já adquiriram durante o seu trajeto no ambiente escolar.

A sequência didática, uma forma sistematizada para trabalhar as práticas de leitura e escrita, é uma ação que os professores podem e devem usar. Com ela, há uma construção de significados e o professsor terá clareza sobre o que vai ensinar. A finalidade de uma sequência didática é precisamente ajudar o aluno a dominar melhor um gênero textual oral ou escrito, permitindo que ele possa se comunicar adequadamente em uma determinada situação. Há uma infinidade de gêneros textuais, com características linguísticas particulares, e isso deve ser levado em consideração na sala de aula. Ao se trabalhar com um gênero específico, o aluno compreenderá as características dele e, assim, poderá produzir seu próprio texto.

Posso citar como exemplo uma atividade que realizei há algum tempo, com alunos do oitavo ano do Esino Fundamental II, de uma escola pública localizada em uma cidade do interior do estado de São Paulo. Primeiramente, foi trabalhado o gênero notícia; suas características foram apresentadas através dos textos dos jornais que os alunos levaram para a sala de aula. Alguns não tinham o material e a escola providenciou o necessário. Os alunos leram e analisaram várias notícias retiradas de alguns jornais de circulação nacional e também do da própria cidade. Juntamente com os jovens, exercendo meu papel de mediadora, fizemos o levantamento das características desse gênero específico e, em

$$
\text { RELEDUC | ISE | v. } 2 \text { | n. } 1 \text { | fev. } 2019
$$


seguida, pedi que escrevessem uma notícia a partir de um fato ocorrido na escola e que eles consideravam importante. Saíram ótimos trabalhos, pois os alunos compreenderam a estrutura do gênero pedido.

Após esse procedimento, foi trabalhado o gênero poesia e todo o processo de leitura e levantamento das características presentes nesse gênero textual foi realizado também. Para finalizar, foi pedido que os alunos transformassem um poema em notícia de jornal, respeitando a estrutura do gênero pedido. Com isso, puderam claramente perceber os elementos específicos de cada gênero trabalhado, bem como as múltiplas finalidades da leitura e da escrita. Houve todo um processo por parte dos alunos para a construção do seu próprio texto, com uma sequência didática e a consciência de que o texto precisa ser refeito quando necessário, o que ocorreu algumas vezes.

Em outras palavras, o professor deve apresentar um problema de comunicação bem definido, na situação inicial, e proporcionar uma sequência de reelaboração, de reescrita do texto até chegar à produção final. Na correção das produções iniciais dos alunos, é primordial o olhar do professor, pois nesse momento ele pode decidir com qual atividade poderá trabalhar com todos os alunos, somente com alguns alunos ou descartála. Nesse percurso, o docente precisa ter a sensibilidade e o discernimento para enxergar as necessidades e dificuldades que os alunos apresentam, para poder ajudá-los na produção do texto oral ou escrito.

O fazer docente inclui não só o conhecimento dos conteúdos da disciplina que o professor leciona, mas também como abordá-los de maneira contextualizada, com o domínio de diferentes métodos de ensino. O professor precisa saber escolher o mais indicado dependendo dos temas abordados e dos alunos com os quais está trabalhando, proporcionando um envolvimento entre alunos/leitores e textos, para despertar no discente o prazer de ler e, quem sabe, transformá-lo em um adulto leitor perene.

\section{CONSIDERAÇÕES FINAIS}

A escola não é obrigada a formar poetas, dramaturgos, romancistas, enfim, escritores, mas cidadãos que saibam ler, escrever, interpretar, para que não sejam meros espectadores da realidade que cerca a todos nós.

Dessa forma, conforme o que foi apresentado neste trabalho, não se pode ter uma concepção redutora de leitura e da escrita dentro da escola. Se isso ocorrer, ela não 
cumprirá sua função, que é formar indivíduos que não sejam apenas reprodutores de significados.

Quanto a produzir um texto, o aluno necessita escrever algo de seu, não apenas repetir frases que ser tornaram clichês. Precisa entender que há boas razões para escrever, do contrário acabará se sentindo desmotivado, inibido diante de situações as quais exijam que ele escreva.

Nesse processo todo, é preciso lembrar também que a responsabilidade não é somente dos professores, pois a organização da escola é relevante. Um ambiente em que o aluno seja respeitado e valorizado faz muita diferença em seu desempenho escolar.

Concluindo, tomo emprestadas as palavras de Silva: "Não há leitor de um texto só e não há leitor de apenas um tipo de texto" (2012, p.14). E o papel do professor e da escola é para que cada vez mais haja uma ampliação dessa ideia. Leitores de muitos textos, de variados tipos e gêneros. E também produtores de textos, de muitos textos, de variados tipos e gêneros. Para que os alunos não se sintam envergonhados diante de situações do cotidiano, nas quais necessitam fazer uso da habilidade de leitura e escrita, nem precisem de olhos e de mãos de outros para realizar essas atividades. Conceitos de leitura, leitores e a relação construída entre eles interessam a todo professor que se acha comprometido com o ato de educar.

\section{REFERÊNCIAS}

ABREU, M. Cultura letrada: literatura e leitura. $2^{a}$ reimpressão. São Paulo: UNESP, 2006. (Coleção Paradidáticos - Série Cultura).

BRASIL. Secretaria de Educação Fundamental. Parâmetros Curriculares Nacionais: Língua Portuguesa de 5a a 8ª́rie. Brasília, DF: MEC/SEF, 1998.

CAGLIARI, Luiz Carlos. Alfabetização e linguística. São Paulo: Scipione, 1989.

CHARTIER, R.. O leitor entre limitações e liberdade. CHARTIER, R. A aventura do livro: do leitor ao navegador. São Paulo: Editora UNESP, 1999. p.75-95.

CINTRA, A. M. Leitura na escola: uma experiência, algumas reflexões. In: ELIAS, V. M. (Org.). Ensino da língua portuguesa: oralidade, escrita e leitura. São Paulo: Contexto, 2011. p.197-204.

DOLZ, J. ; NOVERRAZ, M.; SCHNEUWLY, B. Sequências didáticas para o oral e a escrita: apresentação de um procedimento. In: SCHNEUWLY, B.; DOLZ, J. Gêneros orais e escritos na escola. Campinas, SP: Mercado das Letras, 2004. p. 81-108.

$$
\text { RELEDUC | ISE | v. } 2 \text { | n. } 1 \text { | fev. } 2019
$$


GERALDI, J. W. Portos de Passagem. São Paulo: Martins Fontes, 1993. P. 135-137.

GRIBEL, C. Minhas férias, pula uma linha, parágrafo. Richmond Educação Ltda.,1999. p. 8-9.

KLEBIS, C. E. de O. Leitura na escola: problemas e tentativas de solução. In: SILVA, E. T. da (Org.). Leitura na escola. São Paulo: Global: ALB - Associação de Leitura do Brasil, 2008. P. 33-46.

KLEIMAN, Ângela. Texto e leitor: aspectos cognitivos da linguagem. 5. ed. Campinas-SP: Pontes, 1997.

MAFRA, N. D. F. Literatura dentro fora e à revelia da escola. In: MAFRA N. D. F. Leituras à revelia da escola. Londrina: EDUEL, 2003. p. 31-43.

MARTINS, Maria Helena. O que é leitura. São Paulo: Editora Brasiliense, 1986.

SILVA, E. T. Leitura na escola e na biblioteca: 8. Campinas: Papirus, 2003.

. RPD - Revista Profissão Docente. v.12, n.26. Uberaba, 2012, p.115-119.

Entrevista. Disponível em

www.revistas.uniube.br/index.php/rpd/article/viewFile/564/634. Acesso em 22 de maio de 2017.

. Concepções de leitura e suas consequências no ensino. Perspectiva. v.17, n.31. Florianópolis, jan/jun 1999, p.11-19. Disponível em https://periodicos.ufsc.br/index.php/perspectiva/article/viewFile/10708/10213. Acesso em 26 de fevereiro de 2019.

SOARES, M. B. As condições sociais da leitura: uma reflexão em contraponto. In: ZILBERMAN, R. e SILVA, E. T. da; (Org.). Leitura, perspectivas interdisciplinares. São Paulo: Editora Ática, 2005. p. 7-14. 